\title{
LA SERPIENTE EN EL ARTE RUPESTRE DE Nocui, norte semiárido DE Chile
}

\author{
José Castelleti D. ${ }^{1}$
}

\begin{abstract}
Resumen
Damos a conocer el notable desarrollo técnico e iconográfico que alcanzaron los grabados rupestres de Nocui (región de Coquimbo, Chile), confeccionados desde inicios del Alfarero Temprano (ca. 2000 $\mathrm{AP})$ pero mayormente desarrollados por los diaguitas hasta tiempos tardíos (1000-1536 DC). Su análisis establecerá que el referente serpentimorfo expresa significados que se encuadran en el ámbito de lo simbólico y lo sagrado, siendo el principal indicador de la unidad cultural local. Asimismo, proponemos que el lugar de tales grabados fue dotado de gran valor simbólico, llegando incluso a ser sacralizado, por lo que fue parte esencial de los procesos de apropiación del territorio, conformación de identidad, así como de reafirmación y promoción del imaginario sagrado.
\end{abstract}

Palabras claves: arte rupestre - Nocui - diaguitas - cosmovisión.

Abstract

Rock art research recently conducted at the pastures of Nocui (region of Coquimbo, Chile) reveals the remarkable technical and iconographic development archieved in engravings during early ceramics period (ca. $2000 \mathrm{BP}$ ) and until the blossoming of Diaguita Culture (1000-1536 AD). This suggest that rupestrian expressions played a primary rol in the process of appropriation of the local territory, as carried out through a seasonal hunting and grazing economic strategies. We propose that the high symbolic value attributed in this way to specific locations became sacralized through time, making certaim places essential to the construction of local identity and the promotion of its cosmovision.

Key words: rock art - Nocui - Diaguita Culture - cosmovision.

Recibido: febrero 2008. Aceptado: junio 2008.

\section{* INTROducCión}

En las últimas décadas, en los ámbitos de la arqueología y de la historia del arte ha habido un notable auge en las investigaciones sobre arte rupestre que, desde nuevos enfoques, ha proporcionado nuevas metodologías de análisis que permiten mayores proyecciones en la búsqueda del significado. En Chile, igualmente, se viene configurando una línea de investigaciones post procesuales cuyas fuentes metodológicas y referenciales provienen de la etnohistoria e historia del arte (Gallardo et al. 1990, 1999), de la semiótica (Dettwiler 1986; González 1998a, 1998b) y de la analogía etnográfica y etnohistórica (Berenguer 1998, 1999).

Particularmente en el norte semiárido, la investigación rupestre ha sido desarrollada por Iribarren (1947, 1953 , 1973a, 1973b, 1976), Niemeyer (1964; Niemeyery Mostny 1983, 1991; Niemeyery Castillo 1996; Niemeyery Ballereau 1998) y por el equipo del Museo de La Serena (Ampuero y Rivera 1964, 1971), llegándose a definir los estilos "Limari" en gran parte de las cuencas entre los ríos Elqui y Petorca (Ampuero y Rivera 1964, 1971); Niemeyer y Mostny 1983; Castillo 1985), "La Silla" en el cerro homónimo (Niemeyer y Ballereau 1998), "Quebrada Las Pinturas" en la precordillera de la cuenca del río Salado (Iribarren 1976; Niemeyer y Mostny 1983) y “Aconcagua”, en el curso superior de ese río (Niemeyer 1964; Niemeyer y Mostny 1983). Sin embargo, la óptica funcionalista que predominó para abordar el "estilo" llevó a configurar

\footnotetext{
${ }^{1}$ Universidad Católica del Norte. Casilla 17, San Pedro de Atacama, CHILE. Email: jcastelleti@gmail.com
} 
extensos conjuntos de motivos y técnicas, y a la larga, desarrolló importantes fallas interpretativas, haciendo cada vez más evidentes las falencias metodológicas de estos estudios. La ausencia de un método estandarizado de análisis, la concepción estática de la forma y la falta de reconstrucciones culturales holísticas basadas en estudios interdisciplinarios, fueron sólo algunas críticas que se hicieron al modelo tradicional y que llevaron a la proposición de nuevos enfoques y metodologías (Dettwiler 1986; Gallardo et al. 1990; Troncoso 1998). La falta de claridad respecto del concepto tradicional de estilo que, además, no consideraba el contexto en los procesos de formatividad, llevó a que fuera críticamente revisado y replanteado, para finalmente lograr establecer las reglas de la producción rupestre y su transmisión (Troncoso 2003), sin olvidar sus cualidades estéticas (Dettwiler 1986; Gallardo et al. 1999). De hecho, la denominación de "arte" para este tipo de intervención rupestre obliga a que se le considere un fenómeno estético y comunicativo. Esta reflexión abrió una infinitud de puertas con las llaves de la semiótica, con lo cual se logró apreciar el aspecto básico de este tipo de expresión cultural, cual es la existencia de códigos consensuados que permiten transmitir mensajes expresos o connotados (Eco 1995 [1976]). La búsqueda de estos consensos que otorgan el carácter "comunicativo" al arte rupestre implicó un cambio radical de postura con la cual asumir la existencia de fijaciones de campos de significado en contextos definidos espacial y culturalmente (Gallardo et al. 1990; González 1998a, 1998b; Vilches 2006).

Con la realización de estudios de impacto ambiental (EIA) en la precordillera de la región de Coquimbo (norte semiárido de Chile), fue posible el desarrollo de prospecciones y con ello, una caracterización arqueológica preliminar en las veranadas ${ }^{2}$ de Nocui, registrándose un total de 16 sitios arqueológicos con arte rupestre correspondientes a grabados o petroglifos. Considerando lo expuesto, en este estudio de arte rupestre tomamos como referente la arqueología del paisaje (Criado 1999), y ponemos en práctica una metodología de análisis que posibilitará obtener nexos interpretativos entre el

\footnotetext{
2 Se denomina "veranada" a los sectores cordilleranos con pastos estacionales, donde se lleva el ganado durante el verano.
}

patrón de las expresiones materiales y estructuras de significado de unidades culturales asignables a grupos originarios, tanto actuales como pasados. De acuerdo a ello, seleccionamos el sitio Subida a Veranadas Nocui 4 (SVN-4) para ser muestreado por sus excepcionales y complejas expresiones rupestres.

En Nocui la recurrente expresión del motivo serpentimorfo y su gramática asociada, presumiblemente se originó en los inicios del Alfarero Temprano (ca. 2000 $\mathrm{AP})$ (Castelleti 2004), pero fue mayormente continuada por grupos diaguitas en un extenso lapso temporal para llegar incluso a ser intervenida por grupos diaguitas tardíos (Castillo 1985; Pavlovic y Rodríguez 2005). Creemos que con todo este proceso se está enfatizando la propiedad del territorio por parte de estos grupos que lo intervienen con expresiones rupestres. Éstas se enmarcan dentro de un patrón andino asignable a grupos contemporáneos al Inka (González 1998b, 2000), lo que permitirá interpretarlas dentro de conceptos y patrones del Tawantinsuyo (ca. 1400-1536 DC) conocidos por la etnohistoria, generando una importante fuente de significados con la cual contrastar la evidencia material.

\section{• Aspectos generales del sitio y su entorno}

El sector de Nocui, dado a conocer en la década de los 70 por Iribarren (1973a, 1973b), se ubica en la localidad de Coirón, a $25 \mathrm{~km}$ al este de Salamanca en la región de Coquimbo (IV) de Chile (Figura 1). Corresponde a una extensa meseta formada por conos de deyección y terrazas aluviales del estero homónimo, que se desarrolla entre 1800 a $2100 \mathrm{~m}$.snm bajando abruptamente por el norte hasta el tramo medio del río Choapa y el estero Quelén. El estero Nocui la desagua hacia el Choapa. Este sistema es parte de la cuenca hidrográfica del río Choapa-Illapel, de orientación general este-oeste como es característico en el norte semiárido.

Nocui se extiende por cerca de $5 \mathrm{~km}$ de largo y $1 \mathrm{~km}$ de ancho, siendo estacionalmente cubierto por una gran variedad de gramíneas, razón por la que actualmente es utilizado para llevar a pastar al ganado durante el verano (Figura 2). Su acceso por el sector de Loma Gruesa, entre 


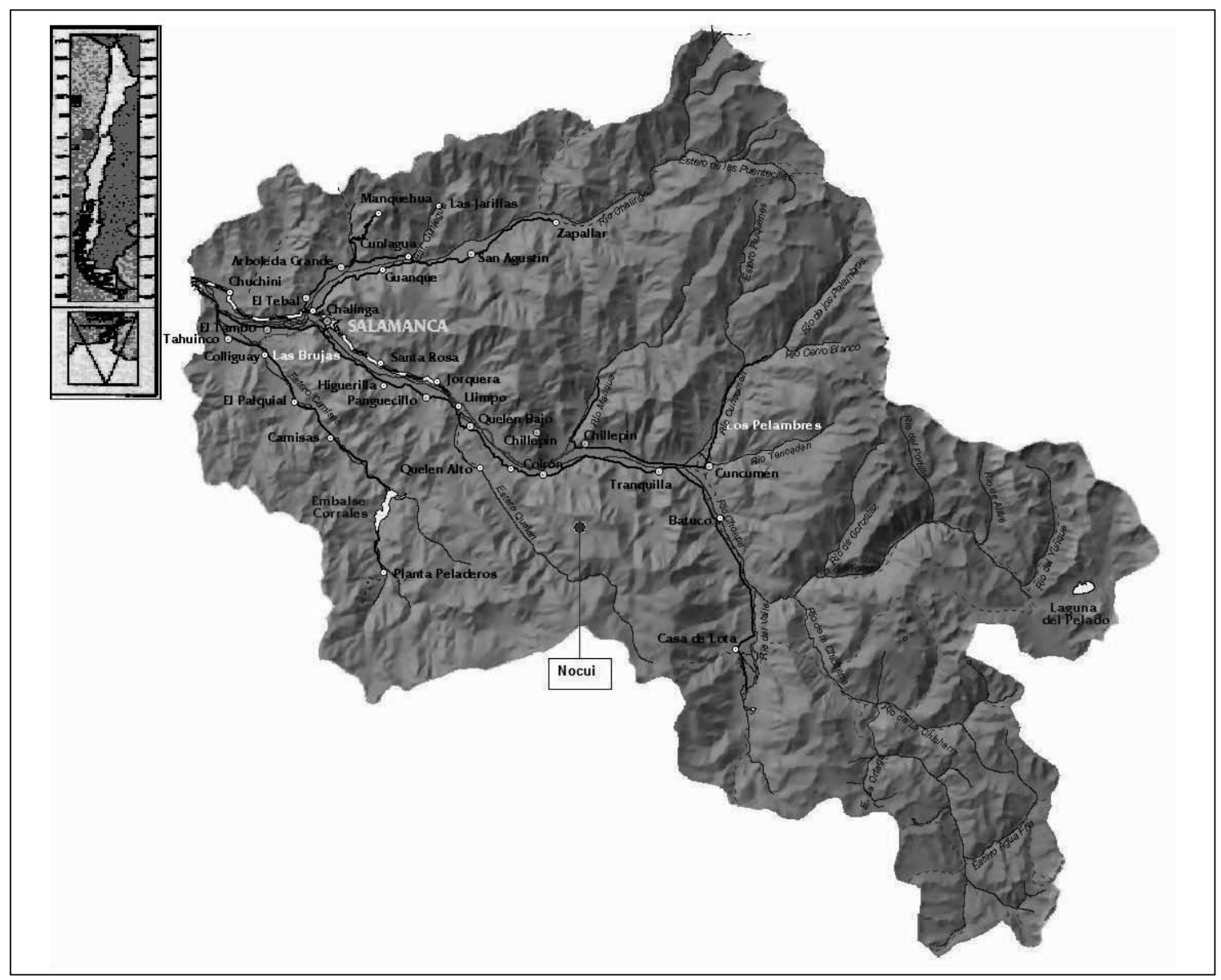

Figura 1. Ubicación de Nocui en el contexto regional.

pequeñas quebradas que cortan una ladera de unos 500 $\mathrm{m}$ de ancho, es bastante abrupto, ya que en no más de 2.5 $\mathrm{km}$ se sube de 800 a $1800 \mathrm{~m} . \mathrm{snm}$. Otras posibles vías de acceso son aún más abruptas y casi infranqueables. En las inmediaciones, a 1426 m.snm, surge la única vertiente estival de agua bebestible a la cual acude no sólo el ganado, sino también la fauna autóctona, entre la que se observa al zorro chilla (Pseudalopex griseus), al chingue (Conrepatus rex), quique (Galictus cuja), varias especies de roedores, de aves, batracios y reptiles (Niemeyer 1989; Jackson et al. 2002). Entre estos últimos hemos visto lagartijas (Liolaemussp), lagarto (Callopistes palluma), culebra de cola larga (Philodryas chamissonis) y culebra de cola corta (Tachymenis chilensis), como también sapos (Bufosp), rana chilena (Caudiverbera caudiverbera) y sapito de cuatro ojos (Pleurodema thaul) (Castelleti 2004). Además, los lugareños cuentan que en épocas de sequía se ha visto al puma (Felis concolor) bajar hasta el sector.
En el pasado, el sistema de asentamiento articuló pequeños campamentos habitacionales estacionales a orillas del estero Nocui, con sectores de talleres líticos, de faenamiento y avistaderos, y una masiva cantidad de paneles utilizados para plasmar arte rupestre en un filón de rocas de andesita basáltica y otras tantas erráticas en las terrazas aluviales del área. Los campamentos habitacionales más permanentes se habrían ubicado en las terrazas bajas del Choapa (700 m.snm), con ocupaciones humanas que, a juzgar por los tipos cerámicos, se hicieron más frecuentes a partir del Alfarero Temprano (Castelleti 2004), desarrollándose una expresión rupestre inicial tradicionalmente definida como estilo Limarí, cuyos indicadores principales son los mascariformes típicos del Choapa (Iribarren 1973a, 1973b), asociaciones de antropomorfos y zoomorfos (Ampuero y Rivera 1964, 1971) y círculos con apéndices (Castillo 1985). 
Del total de 16 sitios arqueológicos con grabados o petroglifos, siete se emplazan en la meseta de altura y nueve en la subida por la ladera norte (Tabla 1). En un solo sitio (Coirón 4) se halló una pequeña pintura en rojo.

\begin{tabular}{|c|c|}
\hline Sitio & $\mathbf{N}^{\mathbf{0}}$ de paneles \\
\hline VN-1 sector 1 & 5 \\
VN-1 sector 2 & 2 \\
\hline VN-2 & 45 \\
\hline VN-3 & 14 \\
\hline VN-4 & 12 \\
\hline VN-5 & 10 \\
\hline VN-6 & 15 \\
\hline SVN-1 & 3 \\
\hline SVN-2 & 5 \\
\hline SVN-3 & 1 \\
\hline SVN-4 sector central & 62 \\
SVN-4 sector marginal & 20 \\
\hline SVN-5 & 3 \\
\hline Coirón-1 & 9 \\
\hline Coirón-2 & 2 \\
\hline Coirón-3 & 2 \\
\hline Coirón-4 & 1 \\
\hline Total & $\mathbf{2 1 1}$ \\
\hline
\end{tabular}

Tabla 1. Nocui: Número de paneles por sitio.
La meseta de altura de Nocui presenta cuatro sitios exclusivamente con arte rupestre y tres con este rasgo en asociación a otros restos materiales. El primero de estos sitios es un pequeño campamento-taller sobre un sector de la terraza oeste del estero, con restos de talla en silíce y andesita, instrumentos para raer y un fragmento proximal de punta de proyectil pequeña de base recta, probablemente alfarero temprana (Castelleti 2004). La mayor depositación de restos líticos se observa en el sitio Veranadas Nocui 2, donde se registraron restos de talla en sílice, basalto y andesita, instrumental lítico para actividades de corte, perforación y raspado, presumiblemente de cueros y carnes, en asociación a los bloques con grabados (Figura 3). También en este sitio registramos escasos fragmentos cerámicos café alisados de espesor delgado y partes de contenedores de líquido, probablemente de tiempos alfareros tempranos. Es probable que esta locación haya sido el campamento base del área en la época estival, ya que en la actualidad corresponde al área nuclear de refugio para arrieros, con una pequeña edificación a no más de $20 \mathrm{~m}$ del estero Nocui. Finalmente, en otro sector de la terraza, el campamento-tallerVeranadas Nocui 5 también evidencia

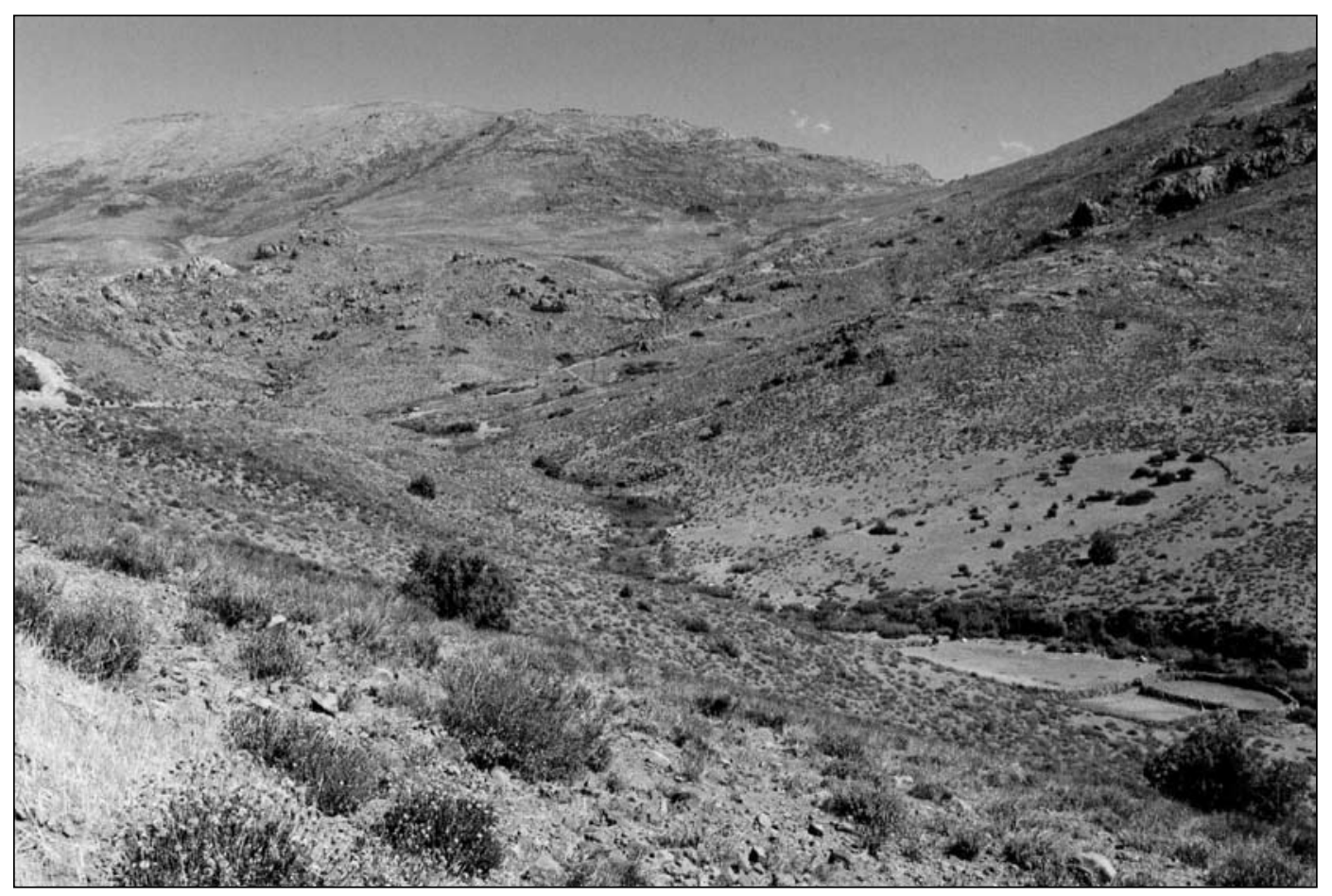

Figura 2. Veranadas de Nocui. 


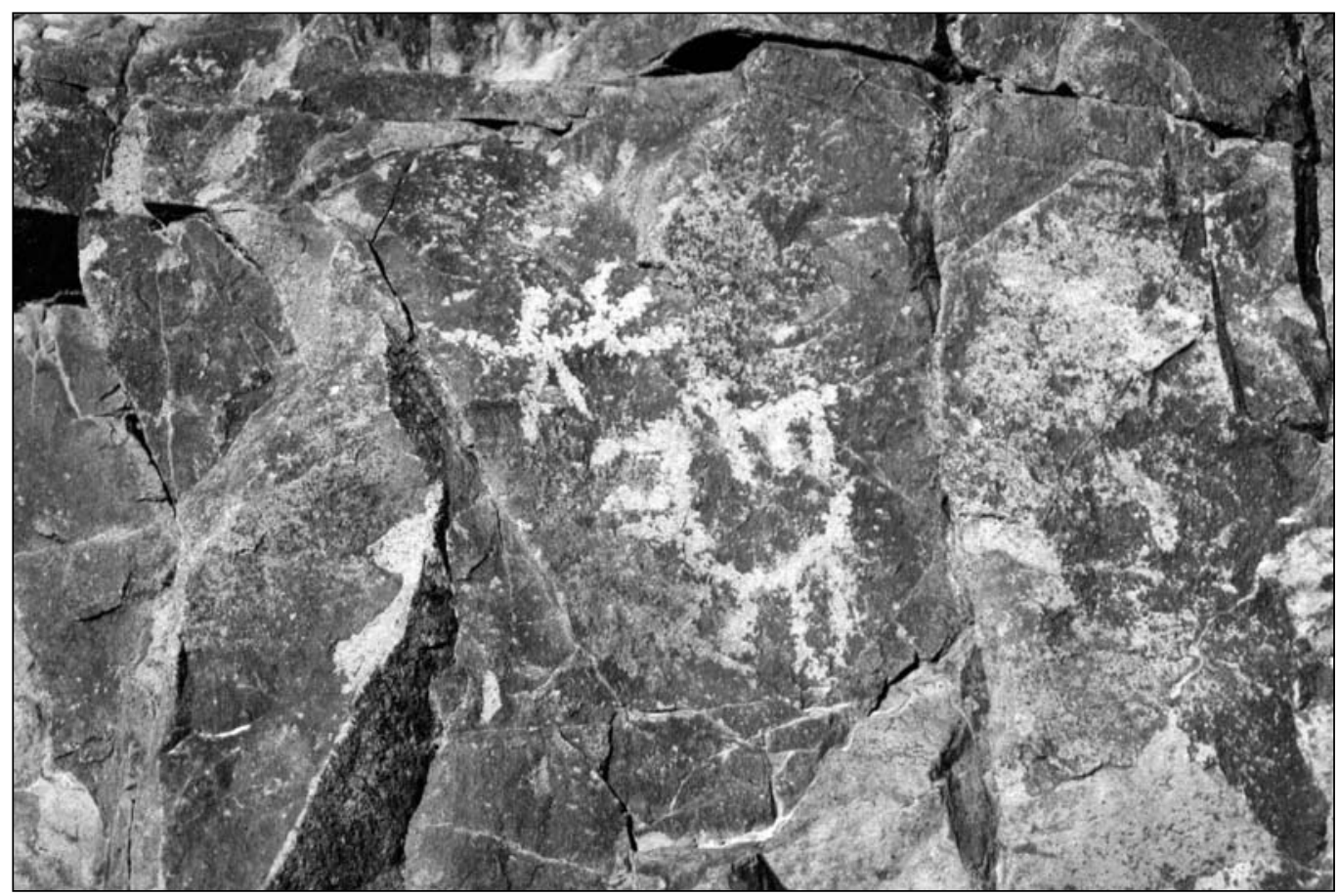

Figura 3. Veranadas Nocui 2 (VN-2).

en superficie escasas actividades de talla y retoque de derivados silíceos y andesíticos, igualmente en asociación con arte rupestre (Casteletti 2004).

Por el contrario, en la subida a las veranadas los sitios se circunscriben a la huella de acceso que serpentea en la ladera empinada. Los nueve sitios hallados en este tramo presentan escasos paneles sobre afloramientos rocosos de dimensiones variadas, siendo la excepción el sitio SVN-4, con una alta densidad de paneles grabados (Tabla 1). Un aspecto importante para el área del acceso es que aquí -salvo en la aguada donde registramos escasos fragmentos cerámicos tempranos-, los sitios no presentan otro tipo de restos asociados. Particularmente el sitio SVN-4 aglutina una gran cantidad de paneles -62 en su área central- ejecutados en un derrubio de andesita basáltica de $100 \mathrm{~m} \times 40 \mathrm{~m}$. En el centro del derrubio se encuentran grandes bloques que, en tiempos pretéritos, podrían haber conformando un alero, hoy colapsado (Figura 4). Tal formación se ubica al inicio del tercio final del acceso norte a Nocui, a $1425 \mathrm{~m}$.snm, justo en medio de dos quebradillas y a unos $100 \mathrm{~m}$ de la vertiente que mencionamos (Castelleti 2004). Por sus peculiares características de emplazamiento y excepcionales expresiones rupestres, elegimos muestrear este sitio para registrar y analizar los motivos que se ven en sus paneles, específicamente en el centro del derrubio, justo en el área de los grandes bloques, ya que aquí es donde se observa la mayor densidad de grabados.

\section{* Los REFERENTES}

Uno de los pasos metodológicos fundamentales y a la vez más problemáticos dentro de los estudios rupestres es, a nivel general, la referencia. Dettwiler (1986) lo denominó "Falacia Referencial", es decir, la manipulación equivocada del campo de su significado, por una confusión en el uso de las "condiciones de significación" vs. "condiciones de verdad" contenidas en su patrón comunicacional. De acuerdo a esto, al producirse una relación codificada entre un campo de significado y una expresión (significante), lo importante no es la "verdad tradicional" que encierra esta relación, sino la intención o el mensaje que ésta conlleva. Tal o cual objeto o concepto que comúnmente ha sido definido con un determinado significado podría ser usado de acuerdo a otra intención (con otro significado) en otro determinado contexto, 


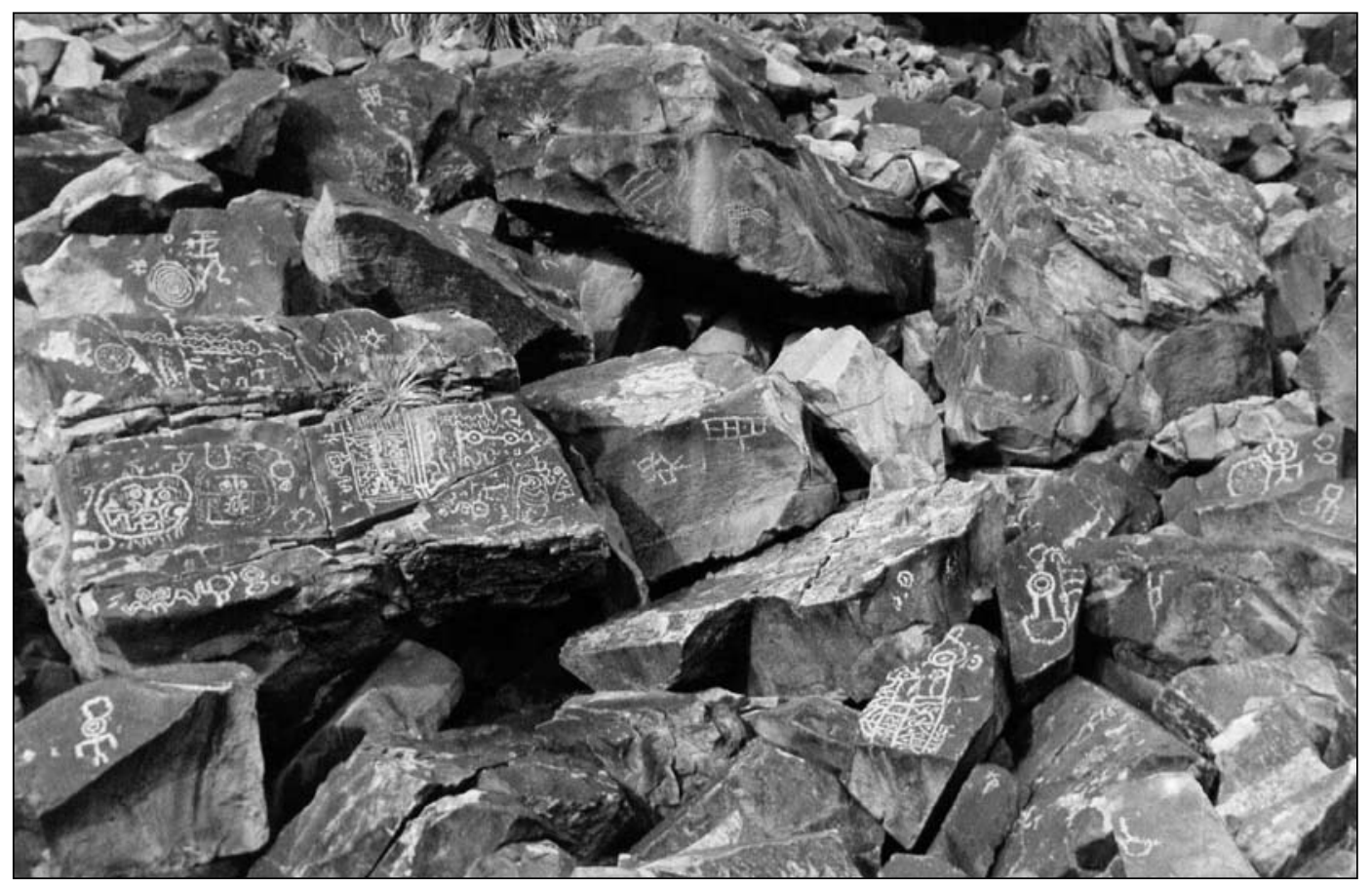

Figura 4. Area central sitio Subida a Veranadas Nocui 4 (SVN-4).

generando en términos semánticos incluso una contradicción u oposición con su definición matriz. Por esto es que el proceso de "producción de signos" no se ajusta a las condiciones de verdad de tal o cual cultura, sino que lo hace a las condiciones de significación en que fueron concebidos, el contexto y las circunstancias en que se produjeron. Entender este proceso implica aceptar el dinamismo inherente a los sistemas de codificación de culturas actuales o pasadas y entender la variabilidad ilimitada en sus procesos creativos (Dettwiler 1986).

Teniendo esto presente, partimos por describir el objeto entregado dentro del mensaje estético, en el conjunto de motivos rupestres del sitio SVN-4, para luego descomponerlos con el fin de llegar a conocer la forma y técnica en que fueron ejecutados. De esta manera, los motivos fueron divididos en: figuras naturalistas (aquellas anatómicamente referenciables a algún objeto de la naturaleza, animado o no) y figuras abstractas (aquellas referenciables a algún objeto ideal), teniendo en un total de 362 motivos registrados en SVN-4, un $24 \%$ relacionado a líneas abstractas, un $14.9 \%$ de motivos serpentimorfos, luego $12.7 \%$ de círculos solos y $11.9 \%$ de círculos con apéndices. En un tercer grupo siguen los mascariformes con $8.3 \%$ y los antropomorfos con $6.9 \%$.
Un cuarto grupo formado por círculos aglutinados continúa con un $3 \%$, y con igual representación, los círculos unidos en línea (posibles serpentimorfos) y las formas indeterminadas. Sigue un quinto grupo formado por referentes escasamente usados (dos a cuatro casos) como los zoomorfos ( $1.1 \%)$, entomorfos (o.8\%), triángulos solos (0.8\%), cuadriláteros o pentágonos unidos (posible antropomorfo) $(0.8 \%)$, puntos (o.8\%), batraciformes $(0.6 \%)$ y escutiformes (0.6\%). El último grupo está constituido por referentes usados en forma única, como es el caso de la impronta de huella de zoomorfo, triángulos en relación abstracta, cuadriláteros unidos en línea, saurio, espiral, círculo cóncavo lateral y letras (estas últimas son intervenciones subactuales).

La gran diferencia entre la frecuencia de motivos naturalistas $(32.9 \%)$ frente a motivos abstractos (63\%) en SVN-4, es la preeminencia del serpentimorfo (segundo en la lista de frecuencias absolutas) (Figura 5), y en menor medida, el mascariforme (Figura 6) evidenciando un fenómeno de relativa "hipercodificación" (Eco 1995 [1976]) en torno a estas figuras destacadas tomadas de la naturaleza. En general, los tamaños de las figuras mantienen una proporción largo/ancho de 1:2, lo que 


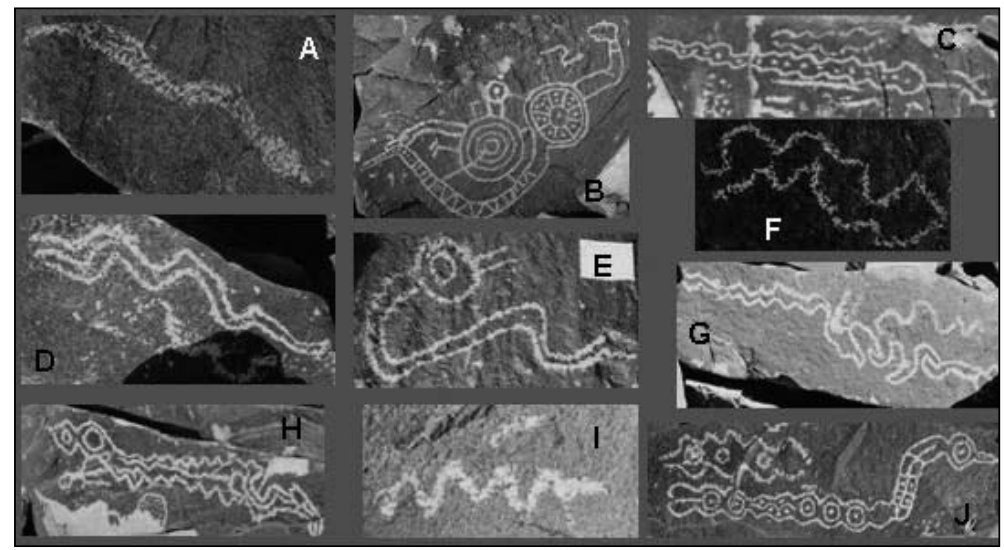

Figura 5. Muestra de serpentimorfos en SVN-4: a) panel 3; b) panel 16; c) panel 43; d) panel 17; e) panel 19; f) panel 6; g) panel 16b; h) panel 14;i) panel 27b;j) panel 16 .

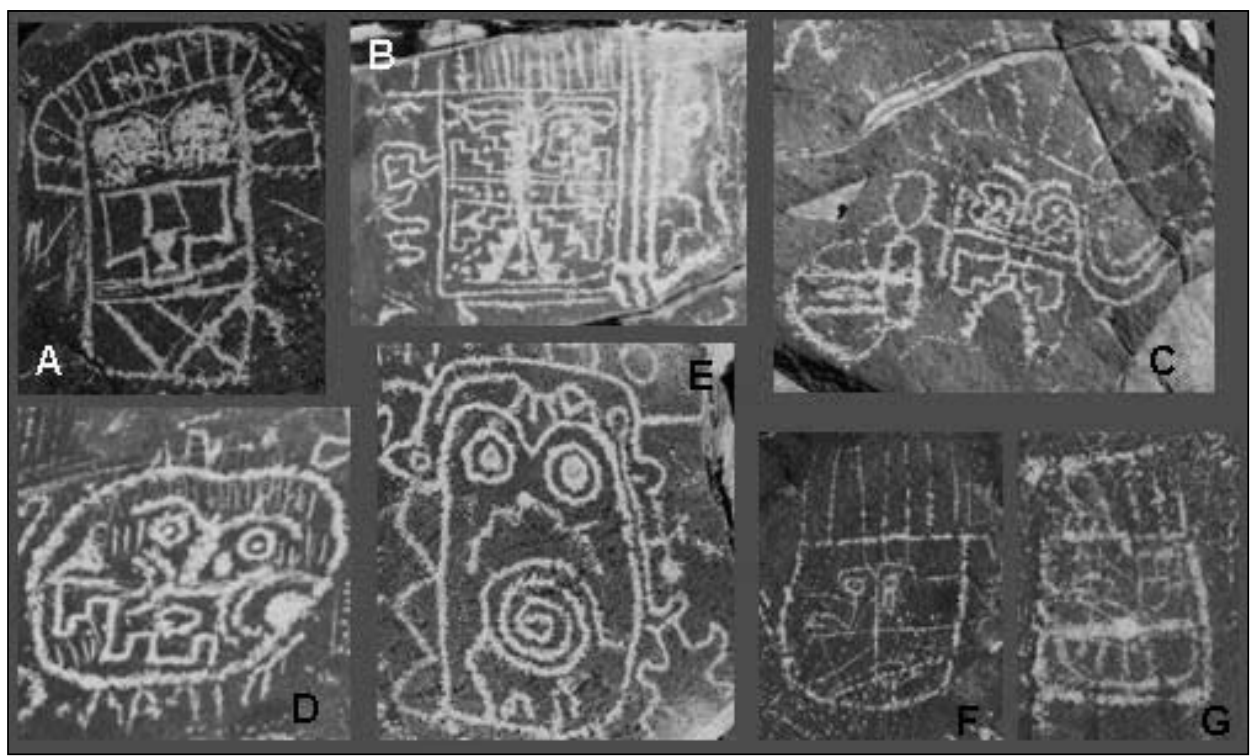

Figura 6. Muestra de mascariformes en SVN-4. a) panel 27; b) panel 43 mascariforme 3; c) panel 57 ; d) panel 43 mascariforme $1 ; \mathbf{e}$ ) panel $1 ; \mathbf{f}$ y $\mathbf{g}$ ) panel 24 .

no sucede con las figuras serpentimorfas y en algunos antropomorfos, ya que en las primeras dicha relación llegará al extremo de 1:10 (Figura 5a). De igual manera, los serpentimorfos son los de mayor largo entre los motivos estudiados, alcanzando hasta $105 \mathrm{~cm}$ en el panel 16 (Figura 7) y un poco menos en otros paneles, en los que destaca el tamaño sólo de algunos antropomorfos (60 cm aprox. en los paneles 10, 11 y 49), siendo los restantes motivos siempre de dimensiones notoriamente menores (Castelleti 2004).
De esta manera, la estructura referencial tomó una serie de figuras de la naturaleza, entre las que destaca el serpentimorfo, que se sobreponen y destacan frente a las abstracciones. Patrones formales estructurados sobre bases de códigos de simetría influyeron en la confección de tales motivos destacados, otorgando la tendencia comunicativa general a SVN-4 y un carácter excepcional a este punto en Nocui que llegó a ser un masivo núcleo de expresión de este arte. 


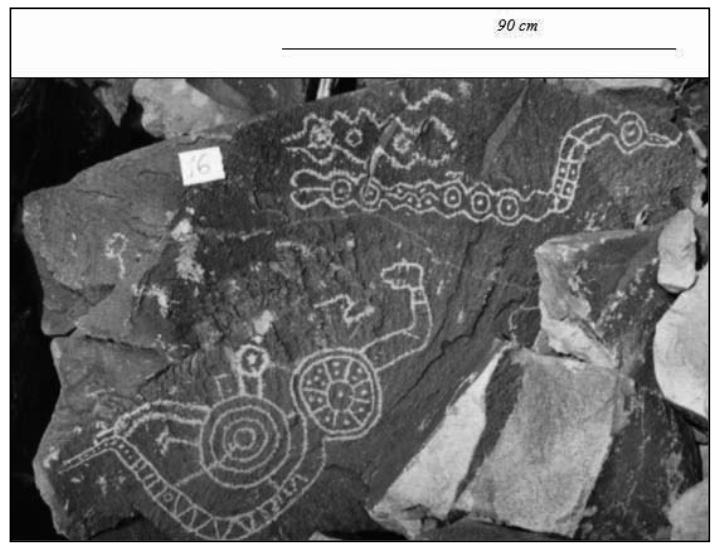

Figura 7. SVN-4, panel 16.

\section{* Secuencia rupestre en Nocui}

Cuando los primeros grupos diaguitas ocuparon el curso medio-superior del Choapa (Pavlovicy Rodríguez 2005), áreas como Nocui ya eran parte del territorio de caza y probable pastoreo estival de las comunidades alfareras tempranas locales, siendo éstas las que crearon muchas de las representaciones rupestres observadas en la zona (Figuras 3 y 8). También es probable que este lugar haya sido sacralizado por dichas comunidades, ya que su estructuración en paneles con cuadros recurrentes que articulaban mascariformes, serpentimorfos, antropomorfos, zoomorfos y figuras abstractas sobresalía como algo excepcional dentro de las tradiciones rupestres altamente esquemáticas de la región, donde tales asociaciones cobraron un papel significativo (Jackson et al. 2002; Cabello $2006 \mathrm{Ms}$ ).
Entonces, siendo ya este lugar parte importante del paisaje y de la cosmovisión local, las comunidades diaguitas lo retomaron y amplificaron, llevando el motivo serpentimorfo a su máxima expresión. Estos grupos de tradición diaguita fueron atraídos por un derrubio rocoso en el acceso a Nocui, cercano al agua del lugary a la huella de acceso, realizando una secuencia de grabados en las rocas patinadas orientadas al norte. Inicialmente prefirieron los tres paneles en el centro del derrubio (paneles 16, 36, 43) para confeccionar espléndidas representaciones de serpientes con cuerpos decorados con motivos en traslación (ver Figura 7), un magnífico zoomorfo sobrenatural (Figura 9) y varios mascariformes decorados (Figura 13). La evidente intencionalidad por destacar estas representaciones por sobre otras de los restantes paneles del sitio, es posible de observar en el gran tamaño en que fueron realizadas, en el hecho de que aparecen solas o en parejas similares, en la decoración interior con motivos en simetría de traslación o reflexión lateral, los que en momentos diaguitas I y II alcanzan gran desarrollo en la región (González 1998b, 2000), y en su recurrencia que produce un efecto de saturación. Como en el resto del área de Nocui, en el acceso la temática se centró en serpentimorfos o bien elementos serpentimorfos, a juzgar por la aparición de rasgos "saurios" en las restantes figuras, como el cuerpo escamoso de un felino (Figura 9) y el decorado facial de un mascariforme (ver Figura 6d).

A partir de este núcleo, en tiempos alfareros intermedio tardíos se desarrollan en forma concéntrica una serie

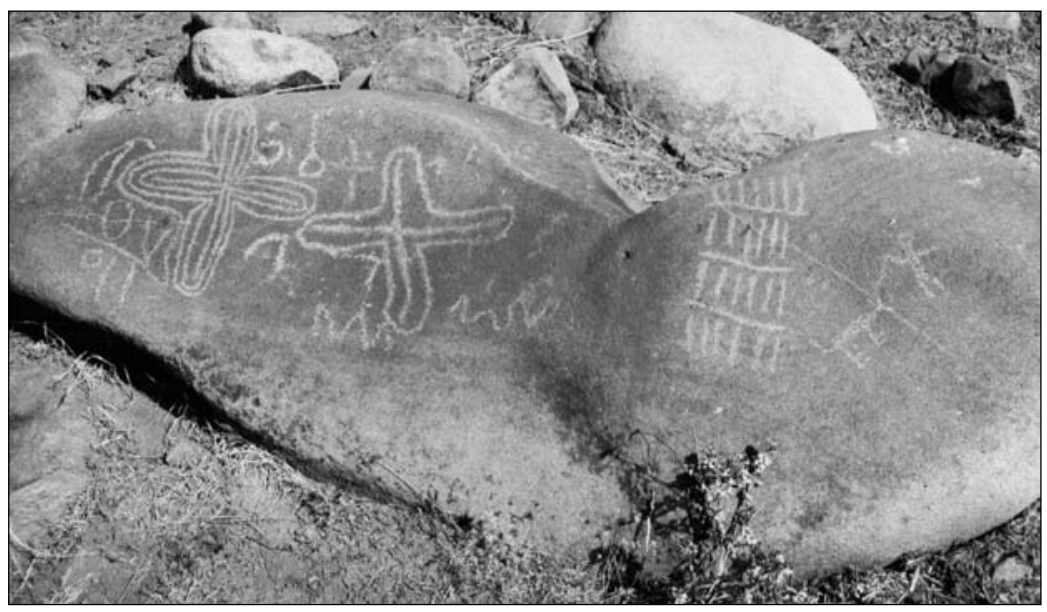

Figura 8. Veranadas Nocui 1 (VN-1). 


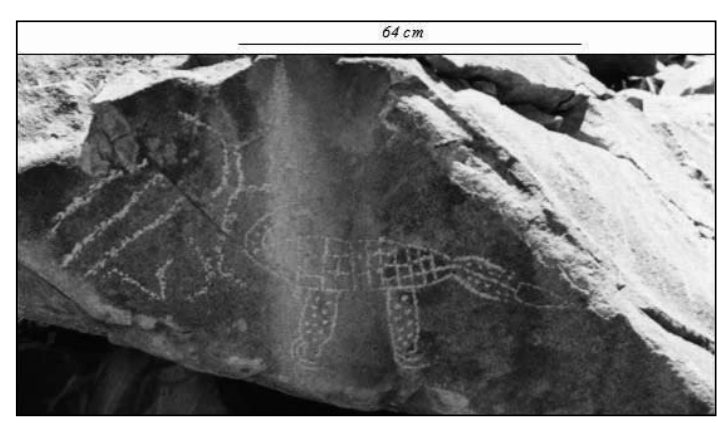

Figura 9. SVN-4, panel 36 .

de expresiones, sin duda articuladas temáticamente, formando una continuidad con los motivos originales transformándolos a su vez. De este modo, en un tercer momento, y emparentadas con aquellas de los paneles centrales, las figuras principales comenzarán a ser articuladas en cuadros temáticos altamente recurrentes, provocando un reajuste de contenido a partir de las nuevas relaciones entre motivos. De aquí en adelante será común la representación de antropomorfos en asociación de yuxtaposición y superposición con serpentimorfos y otras figuras, observándose rasgos decorativos en simetría de traslación (Figuras 10 y 11). Los mismos antropomorfos que sostienen a serpentimorfos poseen rasgos de estos, como por ejemplo, sus extremidades (panel 14) o su cabeza (paneles 10 y 11), destacándose de este modo la representación de las formas de serpiente por sobre el resto. Tanto en los paneles centrales como en las figuras que después

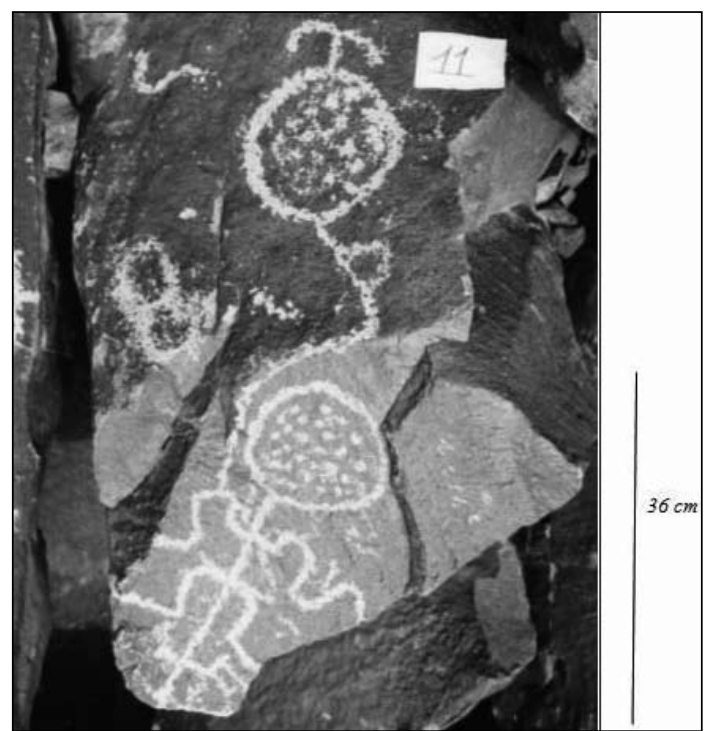

Figura 10. SVN-4, panel 11. se dispusieron en otros paneles a su alrededor, la prolija técnica con que se realizaron líneas anchas y regulares pero poco profundas mediante la percusión con instrumentos no desechables de hueso, madera y piedra, señalaría que hubo grupos especializados en plasmar este tipo de expresiones. En otros paneles que rodean a los centrales se observan figuras similares pero realizadas con técnicas de grabado menos prolijas, con surcos algo irregulares que señalan un menor volumen de extracción y motivos con menor grado de naturalismo, como el saurio del panel 31 (Figura 12), lo que quizás se deba al trabajo de varios autores (Castelleti 2004). También es muy probable que los cuadros de los paneles que rodean a las figuras de los centrales se hayan desarrollado sobre la base de éstas, y que ambos conjuntos hayan estado de algún modo articulados, pues en los dos se grabaron motivos decorativos similares (hileras de círculos con puntos en serpentimorfos) con acabadas técnicas, y en tamaños y proporciones parecidas (serpentimorfos de hasta $1 \mathrm{~m}$ de largo).

Desde ahora, la representación de antropomorfos yuxtapuestos o superpuestos a serpentimorfos será la temática mayormente desarrollada en las siguientes etapas de confección de grabados en torno al centro

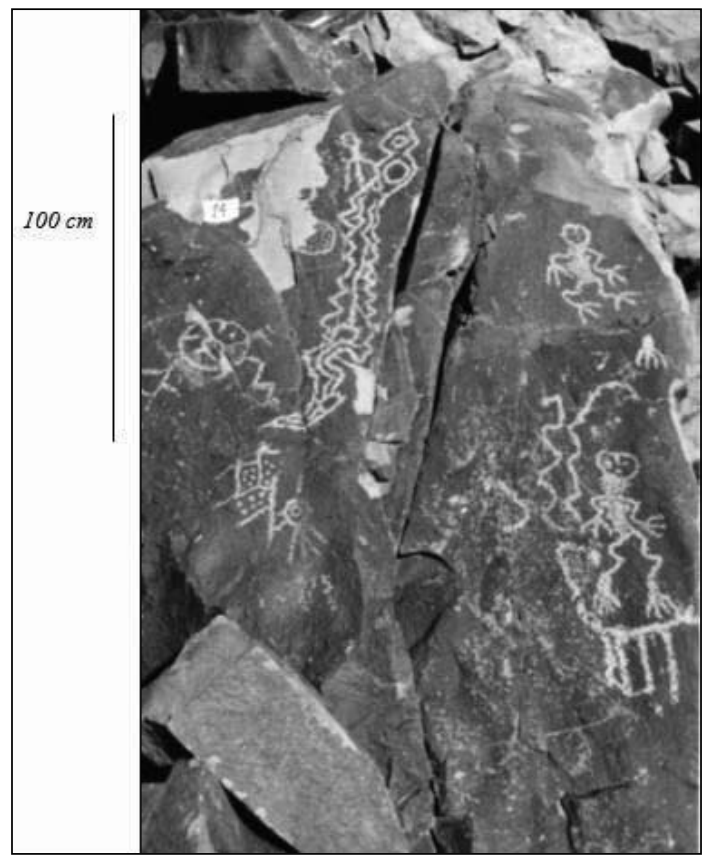

Figura 11. SVN-4, panel 14 . 


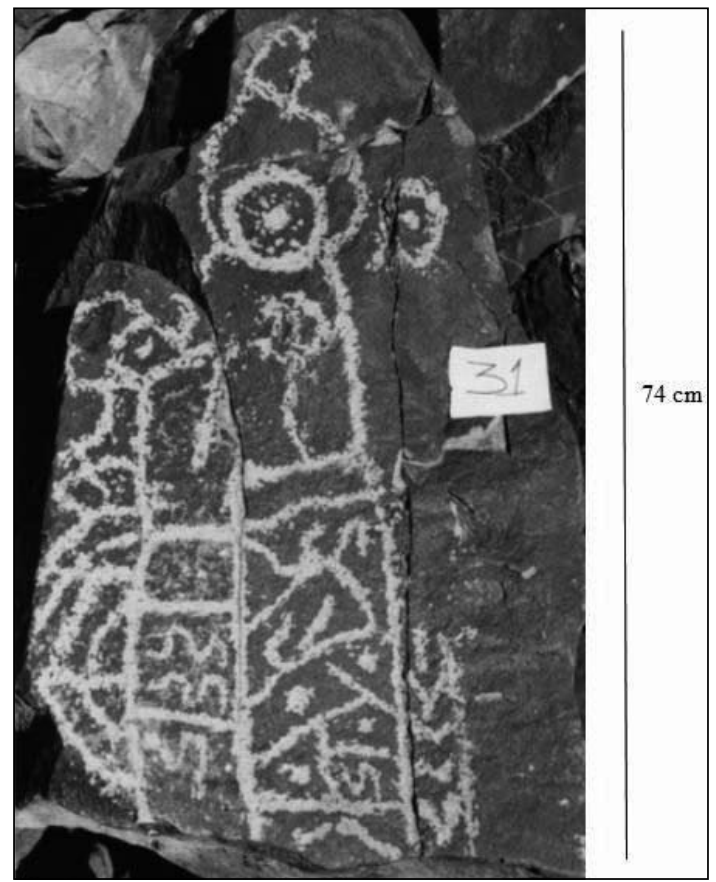

Figura 12. SVN-4, panel 31.

inicial, observándose un proceso de esquematización y estilización de las figuras que, sin duda, es un claro indicador de codificación. Ahora habrá una profusión de paneles grabados de acuerdo a la temática central, y una amplitud de técnicas de confección así como de formas de motivos, generándose la mayor amplitud del área de grabados en el derrubio de la ladera, todo lo cual sugiere una mayor concurrencia de grupos humanos al lugar. Durante este tercer momento empiezan a producirse en el sitio importantes cambios que llevaron a profundizar en la estructuración del código subyacente. Entre estos cambios, el quiebre con el naturalismo de las primeras figuras y una clara tendencia a la abstracción a la vez que un menor tamaño de las mismas, simplifican la forma al asumir un contenido ya definido, proceso que también afectó las técnicas de grabado que ahora realizan surcos más delgados e irregulares, con aún menor volumen de extracción. Es así que la secuencia de paneles de este momento se inicia con cuadros medianamente naturalistas (paneles 19, 28, 29 y 48), continuando con otros con alto grado de abstracción (paneles 8, 9, 21, 15, 52; Figura 17) en los que el serpentimorfo se confecciona a partir de figuras con cuerpo lleno o vacío (ver Figuras $5 \mathrm{a}, \mathrm{d}, \mathrm{e}, \mathrm{f}$ ), hasta llegar a simples líneas sinuosas o curvas (Figura ver 5i) y antropomorfos constituidos por simples círculos solos o con apéndices (Figura 17). La pareja general antropomorfo-serpentimorfo llegará a descomponerse en parejas antropomorfo-antropomorfo o antropomorfozoomorfo, y en casos excepcionales se desarrollará un tema especial con personajes con atuendos (cuerpo manchado en antropomorfo sobre zoomorfo de panel 14; Figura 11) y un cuerpo fitomorfo, que probablemente represente una rama de cebil (Anadenanthera colubrina) (personajes del panel 58; Figura 14), llevando a un clímax la representación de la pareja iniciada en paneles 16, 10 y 11 (Figuras 7 y 10). En estos momentos, tanto la forma como el contenido han llegado a un alto grado de sometimiento a las reglas del código, sin duda por el

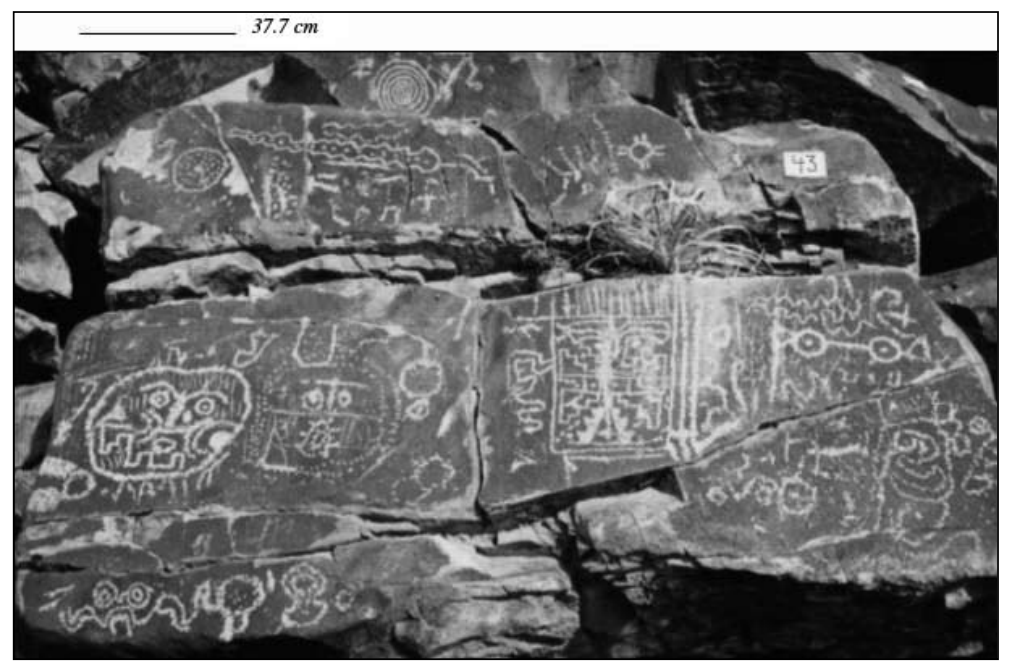

Figura 13. SVN-4, panel 43. 


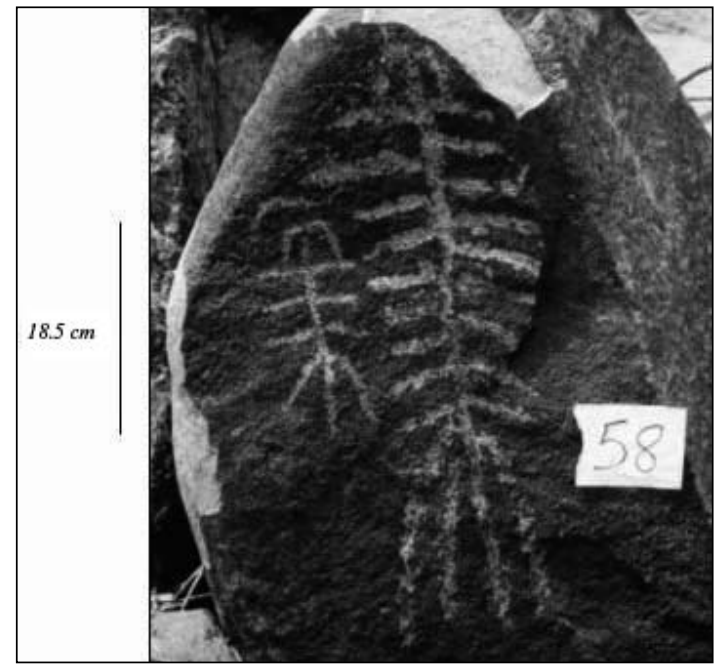

Figura 14. SVN-4, panel 58.

carácter simbólico que le adjudicaron al área los grupos que por aquí transitaron.

Una vez que el sitio estuvo plenamente conformado, en un cuarto momento, técnicas y temáticas bastante peculiares producirán un nuevo reajuste de contenido del código local. En las nuevas representaciones predominará el mascariforme, desplazando al serpentimorfo de esta categoría (paneles 24, 25, 27 y 57; Figuras 15 y $6 \mathrm{a}, \mathrm{f}, \mathrm{g}$ ). Sin embargo, en esta nueva figura predominante lo realmente destacable son las técnicas y los patrones estilísticos, ya que sobre la base de delgadas líneas grabadas y rayadas se realizan rasgos característicos como los perímetros cuadrados, los radiados supracefálicos y los decorados faciales escalerados (principalmente organizados en cuatripartición). Esta ruptura aumenta con la confección por superposición del mascariforme $\mathrm{n}^{\circ} 3$ del panel 43, un arquetipo de este momento que perturbará para siempre a las ancestrales representaciones del sitio (Figura 6b). Los decorados cuatripartitos en los mascariformes, la estandarización en sus patrones formales y la intrusión temática en el sitio, adjudican al sitio al momento diaguita incaico, en el que se observan patrones iconográficos similares en la región (Cornejo 1989; González 1998b, 2000; Cabello 2006 Ms). Por último, los motivos perimetrales de mascariformes con rasgos faciales muy simplificados -vecinos a los cuales se grabaron letras en tiempos históricos (Figura 16)señalan el final de la secuencia.

\section{* Serpentimorfos en el patrón gramatical de LOS MOTIVOS}

Un aspecto característico de los estilos rupestres del norte semiárido corresponde a las técnicas usadas para destacar algunas figuras por sobre otras, ya sea a través del tamaño y proporción, o por sus asociaciones gestuales (Niemeyer y Mostny 1983; Troncoso 1998; Jackson et al. 2002).

En los conjuntos de SVN-4 que exhiben motivos asociados por temática-tamaño destacan figuras que superan en dos o más veces el tamaño máximo de las figuras que las rodean, estas últimas, por lo general, abstractas. La frecuencia de los conjuntos de asociación es la siguiente: figuras destacadas en torno a las que se disponen figuras pequeñas ( 62 casos; $17.1 \%$ ); figuras destacadas en torno a la cual se disponen figuras abstractas ( 58 casos; $16 \%$ ); figuras destacadas vecinas (47 casos; $13 \%$ ); figuras destacadas vecinas a figuras menores (44 casos; $12.1 \%$ ); dos cuadros con figuras destacadas rodeados de figuras menores ( 29 casos; $8 \%$ ), y figuras de tamaño similar vecinas ( 28 casos; $7 \cdot 7 \%$ ).

De un total de 85 figuras consideradas destacadas de acuerdo a los parámetros expuestos, la mayor frecuencia la tienen los mascariformes con $28.2 \%$, seguidos de los círculos con apéndices (18.8\%), los serpentimorfos $(15.3 \%)$ y los antropomorfos (12.9\%). En este contexto, destacamos que el motivo serpentimorfo se ejecuta principalmente inserto en asociaciones del tipo figuras destacadas vecinas (20.4\%), figuras destacadas rodeadas por figuras abstractas (14.8\%), figuras destacadas vecinas a figuras menores (13\%), figuras destacadas rodeadas de figuras menores (13\%), y en otras de menor representación, como figuras solas y superpuestas. Del total de apariciones del motivo serpentimorfo (en 29 paneles), en ocho se asocia a otros motivos destacados antropomorfos (27.6\%), en seis a mascariformes (20.7\%), en cuatro aparece asociado a ambos $(13.8 \%)$, y en tres casos aparece solo (10.3\%).

En tres casos de figuras principales se observan rasgos de dos o tres especies naturales distintas. En dos casos de antropomorfos (panel 14; Figura 11) se registran

\footnotetext{
$\mathrm{N}^{\circ} 36 / 2008$

Estudios AtACAMEÑos

Arqueología y Antropología Surandinas
} 


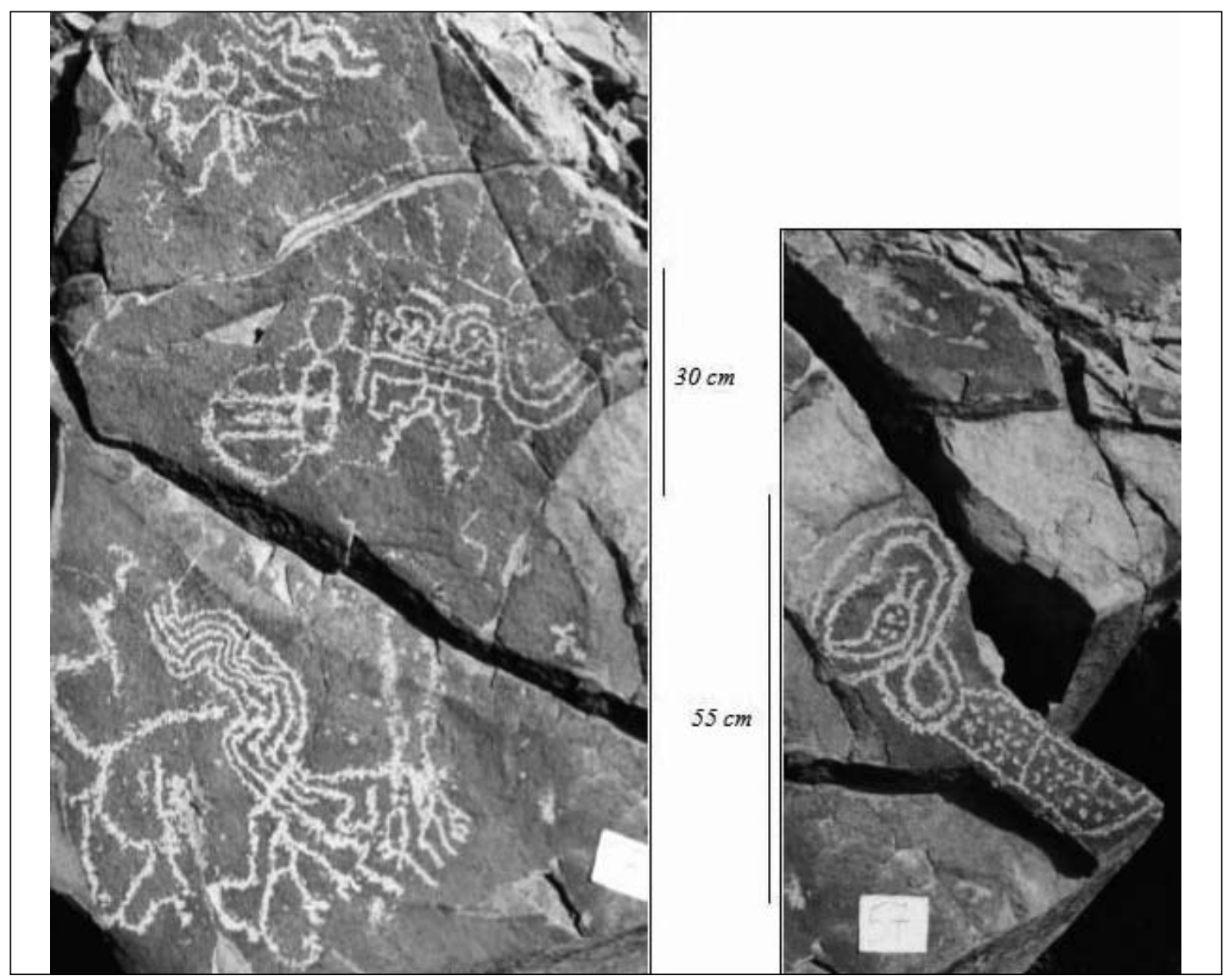

Figura 15. SVN-4, panel 57a.

rasgos anatómicos humanos, batraciformes (manos, pies) y serpentiformes (piernas, brazos), mientras que en tres casos de círculos con apéndices (paneles 10, 11 y 13; Figura 10) se observan rasgos compartidos de dos especies (cabeza antropomorfa y cuerpo serpentimorfo). También se observó un caso (panel 25) de un antropomorfo con manos y pies de batracio o reptil, y un zoomorfo (felino) con cuerpo reticulado como ofidio (panel 36; Figura 9). El reticulado o cuadriculado como decorado corporal se presenta también en el serpentimorfo del panel 31, de acuerdo a lo cual podría interpretarse como una representación de la piel de los ofidios (Castelleti 2004).

Respecto de los rasgos gestuales identificados como representativos de la figura serpentimorfa, podemos observar una frecuente falta de gestualidad ( 46 casos; $85.2 \%$ ) y sólo cuatro casos en que la figura serpentimorfa muestra un gesto de quebrar su cuerpo (paneles 7, 14, 16 y 49; Figuras 7 y 11), y dos casos en que además muestra su lengua (paneles 16 y 19; Figura 7). En sólo un caso la serpiente sólo muestra su lengua (panel 43; Figura 13) y está enroscada y muestra su lengua (panel 57; Figura 15). La relación motivos serpentimorfos/antropomorfos se muestra altamente significativa para la muestra del sitio SVN-4, apareciendo las mencionadas figuras con rasgos de ambas especies (paneles 11 y 14; Figuras 10 y 11), un caso en que antropomorfo está unido a serpentimorfo por trazo sinuoso (panel 10), y cuatro casos en que serpentimorfo se ubica encima de algún sector del cuerpo del antropomorfo, generalmente en disposición transversal (paneles 11, 12, 13 y 28; Figura 10).

Notables figuras antropomorfas en frecuente asociación con serpentimorfos como figuras destacadas evidencian a su vez notables rasgos decorativos preferentemente 


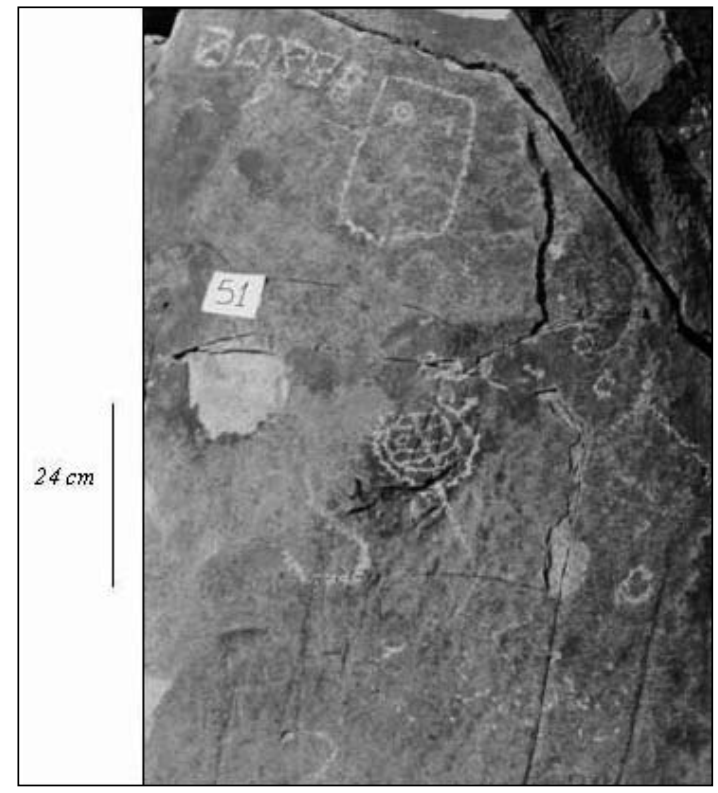

Figura 16. SVN-4, panel 51.

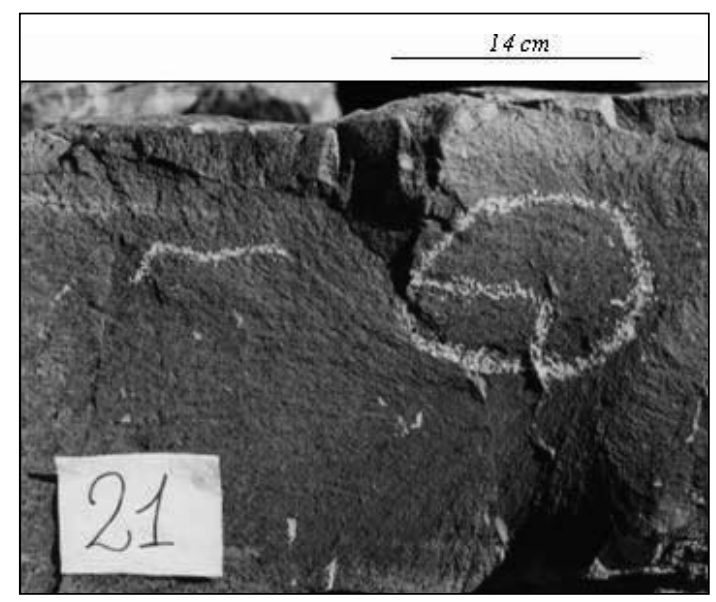

Figura 17. SVN-4, panel 21.

cefálicos, aunque también corporales, como el cuerpo lleno ("moteado" o "manchado") de los antropomorfos del panel 14 (Figura 11), las cabezas felinizadas (con puntos) de antropomorfos destacados con notorios tocados cefálicos (paneles 10 y 11; Figura 10), como la línea bifurcada que se ubica principalmente sobre la cabeza (paneles 11, 28 y 32 ) y a veces perimetralmente (panel 10), y la figura cuadrilátera en paneles 13 y 44 (Castelleti 2004).

\section{$\diamond$ Discusión}

A través del análisis desarrollado hemos podido establecer algunos límites al concepto y referente serpentimorfo, límites dados por su peculiar estructuración en el contexto estudiado en Nocui, por lo cual es posible considerarlo como el principal indicador material de esta unidad cultural local. Derivado de lo anterior es que creemos que este objeto corresponde a la expresión de significados que probablemente se encuadren en el ámbito de lo simbólico y específicamente en el ámbito de lo sagrado en el mundo tradicional indígena, de acuerdo a conductas análogas observadas en otros grupos indígenas prehispanos e históricos (Guevara 1911; Latcham 1929; Llamazares y Martínez 2004).

Es entendido como una alternativa probable el carácter divino o sobrenatural que tuvieron y tienen los grabados o petroglifos en las culturas indígenas, por lo que un carácter similar se podría interpretar para tales expresiones prehispanas en su contexto original. Los estudios llevados a cabo entre los grupos de la Amazonia colombiana (Reichel-Dolmatoff 1985; Evans Schultes y Raffauf 2004 [1992]; Llamazares y Martínez 2004), en la sierra peruana (Latcham 1929) y en otras zonas andinas y selváticas sudamericanas (Furst 1994 [1976]), han generado un conjunto de descripciones que parecen indicar ciertos criterios de identidad grupal que se expresan a través de esta conducta comunicativa humana, transmitida de generación en generación, tal vez con un carácter transcultural.

Uno de los aspectos importantes en la generación de expresiones rupestres es la conformación de una gramática y un significado diferenciado entre motivos abstractos y figurativos (Furst 1994 [1976]), confiriendo a los segundos un carácter destacado de representaciones míticas que "moran o moraron" en áreas geográficas determinadas, sus "seres sobrenaturales" (Evans Schultes y Raffauf 2004 [1992]; Llamazares y Martínez 2004). Un dato coincidente es el registro de una probable asociación entre consumo de sustancias psicoactivas en instancias chamánicas y elaboración de grabados o pinturas rupestres, ya que, si bien se ha perdido hoy el dato de su significado original, grupos indígenas presentan experiencias de

\footnotetext{
$\mathrm{N}^{\circ}{ }_{3} 6 / 2008$

Estudios AtACAMEÑos

Arqueología y Antropología Surandinas
} 
consumo de alucinógenos y la percepción de figuras abstractas y naturalistas relacionadas a su cosmovisión similares a las vistas en petroglifos de su nicho, como mencionan Evans Schultes y Raffauf (2004 [1992]) para la Amazonia colombiana.

Más allá de la ocurrencia o no de ritos chamánicos en Nocui, es significativa la presencia de elementos chamánicos en su arte rupestre (Llamazares y Martínez 2004), como los fitomorfos similares a ramas de cebil (Figura 14) y su articulación a figuras destacadas de carácter mítico (Figuras 7 y 9) y a otras figuras como personajes con rasgos zoomorfos (Figuras 10 y 11 ), rasgos que indudablemente entrañan la adscripción de sus autores a una tradición andina. Lo cierto es que asociaciones de felinos, ofidios, aves y antropomorfos aparecen como recurrentes en la expresión decorativa de la parafernalia asociada a consumo de alucinógenos en gran parte del Area Andina Meridional desde el Formativo (Llagostera et al. 1988; Furst 1994 [1976]), lo cual indudablemente se asocia al concepto que manejaron de su mundo "sagrado" y a su cosmovisión en general. La aparición de una tríada mítica (antropomorfo-felino-serpiente) como patrón general en forma destacada (Castelleti 2004) en el sitio SVN-4 y la oposición temática que muestra con otras áreas de Nocui, que enfatizan otros cuadros abstractos y figurativos como antropomorfos asociados a camélidos (Figuras 3 y 8 ), nos hacen interpretar que este sector para los grupos prehispanos estaría asociado -a lo menos- a un núcleo de expresiones del ámbito mítico o sagrado (Llamazares 2004), tal vez al modo de huaca de la cultura incaica (Latcham 1929). Esto no es del todo descartable con los datos actuales del corpus investigativo, ya que otras áreas con expresiones rupestres se asocian recurrentemente a otras funcionalidades estratégicas como puntos en rutas de movilidad inter e intrarregional (Berenguer 1998, 1999; Muñoz y Briones 1998; Pimentel 2006), a locaciones habitacionales (Jackson et al. 2002; Vilches 2006) o a áreas de pastoreo (Berenguer 1998; Gallardo et al. 1999), observándose en ellas otros conjuntos de motivos destacados dentro de escenas de caravaneo y caza o motivos identitarios, como camélidos o personajes ataviados.
En el contexto macrorregional, uno de los aspectos sustanciales de la representación de tríadas ofidioave-felino en la decoración de vasijas ceremoniales, es que muchas veces corresponden a seres con partes anatómicas diferentes de cada uno de estos animales, en gran parte de los casos antropomorfizados, como sucede en ambas vertientes de los Andes (Rex González 1974, 1998; Cornejo 1989). En Nocui se observan en muchos paneles representaciones con otro tipo de articulación de tres elementos básicos, esta vez con antropomorfos felinizados con extremidades serpentimorfas (paneles 10 y 14), con antropomorfos felinizados asiendo lazos serpentimorfos (panel 11) o la representación enigmática del panel 36 donde aparece un felino ofidizado. No obstante esta variedad, es clara la estructuración de SVN-4 en torno a tres paneles centrales (paneles 43, 36 y 16), en los cuales es representada en forma elocuente la tríada antropomorfo, felino, serpiente, en torno a los cuales se desarrolló el sitio.

Tanto el panel este del sitio (mascariformes, panel 43) como el central (felino, panel 36), orientados al norte y el panel oeste (serpiente, panel 16) que mira hacia el oeste, corresponden a un momento en la vida de Nocui que lleva a sus ocupantes a elaborar complejas y arriesgadas propuestas artísticas, a través de la más expresiva y amplia apropiación de esta área como poseedora de una carga simbólica, que se impuso a escasas expresiones más tempranas del mismo sitio (superposición del panel 14), y sobre todo a las de la meseta de altura. No es descartable que la última etapa de la secuencia rupestre local corresponda a un proceso de dominación por parte del Tawantinsuyo, asumiendo pero "incanizando" las deidades y representaciones de figuras legendarias (Latcham 1929; Troncoso 1998), como sucede en los paneles 24, 25, 27 y 43.

Los procesos decorativos y la gramática expresiva de las representaciones de los paneles centrales habrían sido parte de la inicial apropiación del territorio por grupos diaguitas, los cuales, muy emparentados con grupos Aguada tardíos de la vertiente oriental de los valles andinos (A. R. González 1998), colonizaron la zona del Choapa desde aproximadamente 1000 AP (Troncoso 1998; Pavlovic y Rodríguez 2005; Cabello $2006 \mathrm{Ms)}$. La similitud de 
los esquemas de representación diaguitas con otras áreas del norte semiárido (Cornejo 1989; González 1998b, 2000) en torno a los efectos minimalistas especulares (reflexión lateral unidireccional Diaguita I y II) y su posterior cuatripartición Diaguita III (doble reflexión especular) (González 1998b, 2000), con los observados en los paneles centrales de SVN-4, nos lleva a considerar la adscripción de gran parte de los paneles de la subida de Nocui a este desarrollo cultural, aspectos que se refuerzan al observar la amplia distribución de rasgos zoomorfos y antropomorfos en la decoración cerámica diaguita (Cornejo 1989). La expresión abstracta que significó el minimalismo geométrico decorativo en el mundo ideacional de los grupos locales, observable en la cerámica y también en el arte rupestre, corresponde a principios y conceptos de una cosmovisión que se diferenció de lo temprano - para el ámbito local de Nocui- a través de un acto comunicativo que implicó una ampliación del contenido simbólico del área para los grupos alfareros intermedio tardíos y tardíos y la generación de un punto geográfico de convergencia social.

Al profundizar en torno a la institución andina de la huaca para contrastar la articulación de elementos y rasgos en la expresión del arte rupestre de Nocui, se buscaron modelos y conceptos acerca de lo sagrado evidenciables en relatos míticos incaicos etnohistóricos (Guamán Poma 1980 [1615]; Latcham 1929), cultura que también habría dominado en el área del Choapa. Concibiendo a la huaca como un rasgo natural o antrópico al que se atribuye la residencia de una "fuerza sobrenatural" o donde se puede conectar con ella (Latcham 1929; Eliade 1960), notamos que, en el mundo andino las huacas más comunes corresponden a las pacarinas (lugar de origen de los clanes), evidenciadas en rasgos geográficos como cuevas, ojos de agua o vertientes, aunque comúnmente se describen huacas para la madre tierra (Pachamama), el maíz (zaramama), el ganado (llamamama) o huertos (chacramama) (Latcham 1929). En muchos casos las huacas se asocian a animales o elementos naturales que destacan sus cualidades, incluso en templos y ciudades. Complementariamente, ciertos mitos incaicos y calchaquíes asignan un lugar particular a la serpiente como figura destacada. Dentro del panteón inca se ubica Chuquiylla o Illapa, fuente de truenos, relámpagos y rayos, fuerza antropomorfizada que posee la cualidad sobrenatural de producir rayos (o piedras de rayo) como descargas rápidas símil de serpiente desde su honda y que además, se expresa con fuertes ruidos y luz desde su boca (Latcham 1929). Coincidentemente una deidad similar entre los calchaquíes históricos corresponde a Huayropuca (Guevara 1911), entidad con cabeza humana y cuerpo de serpiente, varón y hembra a la vez, que corre por los aires llevando el huracán, la tormenta y la lluvia (Latcham 1929).

Como huaca creemos, la estructura de la representación rupestre en el acceso a Nocui parece indicar la presencia metafórica o metonímicamente (Eco 1995 [1976]) de esferas de significado donde entidades sobrenaturales definen, a la vez que articulan, la cosmovisión de sus autores.

En Nocui también es una figura antropomorfa o mascariforme la que detenta cualidades de serpientes, como en los paneles 10, 11 y 13 de SVN-4, donde antropomorfos sostienen en un brazo un objeto similar a una honda y en el otro lazos serpentiformes. Preferentemente asociada a lluvias y tormentas, la divinidad inca de Illapa se contrapone a las de Viracocha e Inti, detentadoras de un escalafón mayor al corresponder a la religión de la élite gobernante del Cusco (Latcham 1929) y poseedoras de una estructura de representación diferente.

Por otra parte, nuevos aportes han sugerido y luego corroborado la conexión entre las expresiones artísticas tradicionales y su mundo ideacional y simbólico, su "mundo sagrado" como parte de su cosmovisión (Eliade 1960), entendiendo esta relación como la manera de fijar en sus mentes la apropiación del entorno, en el fondo, fijando su identidad a través de un proceso de materialización y semantización (Jones 1996, 1997; Criado 1999). En este ámbito, el concepto de texto estético pasa a ser el método más eficaz para adentrarse en las esferas del arte y los fenómenos de cambio que pueden suceder en éste (p.e., hiper e hipo codificación) que amplían o restringen el significado (Eco 1995 [1976]). Según la perspectiva indígena tradicional, como enfatizamos, gran parte de las creaciones materiales humanas que podrían considerarse arte, además de la aplicación de 
un desarrollo técnico en su ejecución, son consideradas instrumentos de diálogo con lo sagrado (Eliade 1960; Llamazares y Martínez 2004). Asumimos entonces esta cualidad, entendiendo operativamente un proceso comunicativo de fijación de su significado y la materialización de pautas de un código cultural. Por esto es que el arte rupestre pasa a conformarse como uno de los más genuinos exponentes de esta cualidad cultural prehispana, ya que corresponde a una conducta masificada como evidencia del registro arqueológico existente. El arte rupestre, por tanto, se interpreta como un importante vehículo de transmisión de cosmovisión en el entorno social (Llamazares 2004). Con esto, el estudio actual de los códigos de producción del arte rupestre en el mundo andino ha permitido avanzar en la determinación de aspectos claves en la identidad de los grupos humanos pretéritos, lográndose interpretar la asociación de ciertos patrones a rutas de caravaneo (Berenguer 1998; Pimentel 2006), a ámbitos domésticos (Vilches 2006) o a lugares rituales (Chacama y Muñoz 1991).

Uno de los aspectos más controvertidos en los estudios de cosmovisión lo constituye la evidencia de chamanismo y consumo de alucinógenos en contextos rituales. Más aún lo es la asociación entre consumo de sustancias psicotrópicas y sitios con arte rupestre, aunque en el mundo andino, el emplazamiento de este tipo de sitios corresponde más bien a lugares donde se expresa información concebida en contextos chamánicos, información por supuesto enmarcada en la funcionalidad del área (Llamazares 2004). El simbolismo expresado en sitios asociados a rutas de caravaneo es bastante distinto al expresado al interior de ámbitos domésticos, y muy distinto a lo observado en huacas. No obstante, el proceso que ha posibilitado la confección de arte rupestre en todos los casos, es la corroboración consensuada de espacios de información del ámbito simbólico, que se desarrolla como la confirmación de ciertos mitos (Eliade 1960; Furst 1994 [1976]), un recordatorio y contrastación de una historia traspasada de generación en generación, que ayuda a mantener la cohesión del grupo en torno a conceptos de identidad y a su vez de apropiación del entorno tanto físico como ideacional.
Las figuras con partes anatómicas de dos o más especies ha sido el patrón de expresión más representativo de los contextos chamánicos, siendo interpretadas como parte del proceso de transformación del chamán en otra u otras especies, o la expresión del vuelo extático del chamán en ritos con o sin consumo de sustancias psicotrópicas (A. R. González 1998; Llamazares 2004). Normalmente esta estructuración mítica se materializa en antropomorfos con rasgos de otras especies animales como serpientes o felinos (Llagostera et al. 1988; A. R. González 1998), o por figuras anatrópicas u opuestas (A. R. González 1974, 1998), ejecutados tanto en arte rupestre como en otros soportes. Los cuadros de algunos paneles de SVN-4 (paneles 10 a 15) muestran personajes antropomorfos con atributos de otras especies de animales, o figuras con atributos de serpiente y felino (panel 36), lo cual podría tratarse de la representación de ritos chamánicos en relación a la fuerza sobrenatural que vive en esta huaca (Latcham 1929), en los cuales los personajes adquieren rasgos felinos (cuerpo moteado) o serpentimorfos (lengua bífida, piel reticulada o extremidades serpentiformes), connotando el poder o prestigio del ejecutante en relación a esta esfera simbólica (Llamazares 2004).

Con el tiempo, los sitios con arte rupestre son resemantizados por los nuevos pobladores, asimilando y transformando antiguos mitos o insertando al bagaje cultural otros nuevos. En los Andes Meridionales muchos de los sitios rupestres fueron extirpados de los circuitos de rogativas indígenas y sometidos a la anulación moral de acuerdo a la ideología católica de los conquistadores (Guamán Poma 1980 [1615]), proceso que continuó en periodos históricos más recientes como lo atestiguan las numerosas intervenciones católicas en sitios como los del cerro Tongorito (Niemeyer y Mostny 1991). Es probable, finalmente, que los sitios con arte rupestre del norte semiárido continuaran relacionados con fuerzas sobrenaturales entre la población local desde momentos históricos, ya que se estima que las creencias en relación a lo sagrado aún no han desaparecido de la cosmovisión indígena tradicional. El código rupestre de esta manera se transforma, pero no desaparece. 


\section{$*$ Conclusiones}

La consideración del significado en el registro y análisis de los motivos presentes en los paneles del sitio SVN-4 y de un transecto trazado en Nocui posibilitó la aplicación de una metodología de aproximación que ha dado cuenta en forma eficaz del contexto observado en otras unidades culturales de la región, permitiendo la comparación entre niveles intrasitio como intersitios (Troncoso 1998, 2003). Las características materiales de los motivos en los paneles y su contexto de asociación como significantes se reflejan y por tanto verifican en un ámbito definido de significado, ya que ambos campos prefiguran una articulación de patrones consensuada y complementaria. Esta asociación relativa, a la vez que aislada en el mundo, comenzó a repetirse en un área como parte del proceso de desarrollo de la identidad que definió sus ocupaciones humanas, aspecto netamente determinado por el juego de poderes dentro de los grupos debido a oposiciones etarias, genéricas o grupos de tarea especializados en aspectos económicos o simbólicos, mediante pautas, no importando la calidad del ejecutor, salvo en cuanto a la capacidad de incluir detalles que aporten a fijar cualidades del mensaje. Al considerar las expresiones rupestres de Nocui como un texto estético (Eco 1995 [1976]; Dettwiler 1986), se asume una manipulación de la expresión que provoca y es provocada por un reajuste de contenido, operación que genera un proceso de cambio de código, “...el texto representa un retículo de actos comunicativos encaminados a provocar respuestas originales" (Dettwiler 1986: 455). Estas conductas resultarían en dos aristas en cuanto a la estructuración de su significado: la configuración de un código local y su articulación a megaprocesos ocupacionales de amplitud regional, cuyas raíces, como hemos mencionado, se remontan al Alfarero Temprano y se consolidan en el Tardío (ca. 2000-500 AP).
Por otra parte, los trabajos estadísticos llevados a cabo en SVN-4 permitieron establecer un proceso de extensión o apropiación de la locación en forma concéntrica en torno a las figuras principales, observándose una evolución notoria de gramática y técnica. Lo anterior nos lleva a considerar la concurrencia al lugar de variadas oleadas de confección, de ejecutores especialistas y no especialistas como lo pueden ser exploradores, negociadores y chasquis, que terminaron por fijar la apropiación del lugar.

De acuerdo a lo anterior, es posible considerar al lugar como un punto sagrado de momentos preincaicos e incaicos, centrado en una fuerza mítica que reside en el derrubio cercano a la aguada, que nucleó una rogativa de grupos variados en el tiempo, probablemente debido al prestigio que como huaca adquirió. En efecto, la variedad de diseños en el sitio y su estructuración nos hace suponer la concurrencia de grupos de zonas como el Aconcagua Superior y Chincolco, dadas las similitudes en algunos de los motivos observados (Niemeyer 1964; Niemeyer y Mostny 1991). El sitio, si bien de emplazamiento más bien privado, se asocia cercanamente (100 m) a la huella que une Nocui con el Choapa, Chincolco y Aconcagua a través de la cual se vincularía también con otras zonas más lejanas, como Limarí y la vertiente andina oriental. A la llegada de los incas al área de Nocui, y la consecuente apropiación de la huaca que significó SVN-4, ésta presentaba una variada conjugación técnica y estética en sus representaciones, fruto de la mencionada concurrencia regional del Intermedio Tardío y variadas manos en su confección.

Agradecimientos A toda la comunidad de Coirón (Choapa) y a las comunidades de Chincolco, Pedernal y el Sobrante (Petorca), con quienes aprendí a mirar los dibujos en las piedras. Desde la lejanía también a todos los que me han ayudado en este camino: Carlos González, Claudia Silva, Francisco Gallardo, Rodrigo Mera y Patricio Galarce. 


\section{- Referencias citadas}

Ampuero, G. y M. Rivera, 1964. Excavaciones en la quebrada El Encanto, depto. de Ovalle (informe preliminar). Actas del III Congreso Nacional de Arqueología Chilena, pp. 207-217. Santiago.

1971. Las manifestaciones rupestres y arqueológicas del valle del Encanto. Publicaciones del Museo Arqueológico de La Serena, Boletín 14: 71-103.

Berenguer, J., 1998. Identificación de camélidos en el arte rupestre de Taira: ¿Animales silvestres o domésticos?. Chungara 28: 85-114.

1999. El evanescente lenguaje del arte rupestre en los Andes atacameños. En Arte rupestre en los Andes de Capricornio, J. Berenguer y F. Gallardo Eds., pp. 9-56. Museo Chileno de Arte Precolombino, Santiago.

Cabello, G., 1996 Ms. De rostros a espacios compositivos. Una propuesta estilística para el valle de Chalinga, Chile.

CAstelleti, J., 2004. El arte rupestre de Nocui en el Choapa. Memoria de Título. Departamento de Antropología, Universidad de Chile, Santiago.

CAstillo, G., 1985. Revisión del arte rupestre molle. En Estudios en arte rupestre, C. Aldunate, J. Berenguer y V. Castro (Ed.), pp. 173194. Museo Chileno de Arte Precolombino, Santiago.

Cornejo, L., 1989. El plato zoomorfo diaguita: Variedad y especificidad. Boletín del Museo Chileno de Arte Precolombino 3: 47-80.

Criado, F. (Ed.), 1999. Del terreno al espacio: Planteamientos y perspectivas para la arqueología del paisaje. Capa 6.

ChaCAMA, J. e I. MuÑoz, 1991. La cueva de La Capilla: Manifestaciones de arte y símbolos de los pescadores arcaicos de Arica. Actas del XI Congreso Nacional de Arqueología Chilena, pp. 37-41. Temuco.

DetTwiler, A., 1986. Análisis del arte rupestre, entre la miopía funcionalista y el imperialismo de la semiótica. Chungara 16-17: 451-458.

ECO, U., 1995 [1976]. Tratado de semiótica general. Editorial Lumen, Barcelona.

Eliade, M., 1960. El chamanismo y las técnicas arcaicas del éxtasis. Fondo de Cultura Económica, México D. F.

Evans Schultes, R. y R. F. Raffauf, 2004 [1992]. El bejuco del alma. El Ancora Editores, Fondo de Cultura Económica, Bogotá.
Funst, P. T., 1994 [1976]. Alucinógenos y cultura. Fondo de Cultura Económica, México D. F.

Gallardo, F., V. Castro y P. Miranda, 1990. Jinetes sagrados en el Desierto de Atacama: Un estudio de arte rupestre andino. Boletín del Museo Chileno de Arte Precolombino 4: 27-56.

Gallardo, F., C. Sinclaire y C. Silva, 1999. Arte rupestre, emplazamiento y paisaje en la cordillera del Desierto de Atacama. En Arte rupestre en los Andes de Capricornio, J. Berenguer y F. Gallardo (Eds.), pp. 57-96. Museo Chileno de Arte Precolombino, Santiago.

Guevara, T., 1911. Folklore araucano. Imprenta Cervantes, Santiago.

González, A. R., 1974. Arte, estructura y arqueología. Ediciones Nueva Visión, Buenos Aires.

_ 1998. Cultura La Aguada. Filmediciones Valero, Buenos Aires.

González, P., 1998a. Códigos visuales en las pinturas rupestres de la subregión del río Salado, norte de Chile. Monografías de Museo Chileno de Arte Precolombino 1. En prensa.

1998b. Doble reflexión especular en los diseños cerámicos diaguita-inca: De la imagen al símbolo. Boletín del Museo Chileno de Arte Precolombino 7:39-52.

2000. Patrones decorativos de las culturas agroalfareras de la provincia del Choapa y su relación con los desarrollos culturales de las áreas aledañas (Norte Chico y Zona Central). Contribución Arqueológica 5, vol. 2, pp. 191-221.

Guamán Poma de Ayala, F., 1980 [1615]. El primer nueva corónica y buen gobierno, J. Murra y R. Adorno (Eds.). Siglo XXI, México D. F.

IrIbarRen, J., 1947. Los petroglifos del valle del río Hurtado. Publicaciones de la Sociedad Arqueológica de La Serena, Boletín $3: 1-3$.

1953. Petroglifos en las estancias de La Laguna y Piedras Blancas (río Hurtado). Publicaciones del Museo y de la Sociedad Arqueológica de La Serena, Boletín 7: 1-4

1973a. Pictografías en las provincias de Atacama y Coquimbo, Chile. Publicaciones del Museo Arqueológico de La Serena, Boletín 15: 115-132.

1973b. Geoglifos, pictografías y petroglifos de Chile. Publicaciones del Museo Arqueológico de La Serena, Boletín 15: 133-159. 
1976. Arte rupestre en la quebrada de Las Pinturas (III región). Homenaje al Dr. Gustavo Le Paige s.j., J. M. Casassas (Ed.), pp. 115-126. Universidad del Norte, Antofagasta.

Jackson, D., D. Artigas y G. Cabello, 2002. Trazos del Choapa.Arte rupestre de la cuenca del río Choapa, una perspectiva macroespacial. Depto. Investigación y Desarrollo, Universidad de Chile, Santiago.

JONES, S., 1996. Discourses of identity in the interpretation of the past. En Cultural identity and archaeology: The construction of European communities, P. Graves-Brown, S. Jones y C. Gamble (Eds.), pp. 62-80. Routledge, Londres.

1997. The archaeology of ethnicity. Constructing identities in the past and present. Routledge, Londres y Nueva York.

Latcham, R., 1929. Las creencias religiosas de los antiguos peruanos. Establecimientos Gráficos Balcells \& Co, Santiago.

Llagostera, A., C. Torres y M. A. Costa, 1988. El complejo psicotrópico de Solcor 3 (San Pedro de Atacama). Estudios Atacameños 9: 61-98.

Llamazares, A. M., 2004. Arte chamánico: Visiones del universo. En El lenguaje de los dioses. Arte, chamanismo y cosmovisión en Sudamérica, A. M. Llamazares y C. Martínez (Eds.), pp. 67-125. Editorial Biblos, Buenos Aires.

Llamazares, A. M. y C. Martínez, 2004. El lenguaje de los dioses. En El lenguaje de los dioses. Arte, chamanismo y cosmovisión en Sudamérica, A. M. Llamazares y C. Martínez (Eds.), pp. 13-20. Editorial Biblos, Buenos Aires.

Muñoz, I. y L. Briones, 1998. Poblados, rutas y arte rupestre precolombinos de Arica: Descripción y análisis del sistema de organización. Chungara 28: 47-84.

Niemeyer, H., 1964. Petroglifos en el curso superior del río Aconcagua. Actas del III Congreso Nacional de Arqueología Chilena, pp. 133-150. Santiago.

1989. El escenario geográfico. En Culturas de Chile. Prehistoria desde sus orígenes hasta los albores de la Conquista, J. Hidalgo, V. Schiappacasse, H. Niemeyer, C. Aldunate e I. Solimano (Eds.), pp. 1-12. Editorial Andrés Bello, Santiago.
Niemeyer, H. y D. Ballereau, 1998. Los petroglifos del cerro La Silla, región de Coquimbo. Chungara 28: 277-317.

Niemeyer, H. y G. CAstillo, 1996. Los yacimientos arqueológicos del estero de San Pedro de Quiles (comuna de Punitaqui, provincia del Limarí). Boletín del Museo Arqueológico de La Serena 19: 53-88.

Niemeyer, H. y G. Mostny, 1983. Arte rupestre chileno. Publicación del Departamento de Extensión Cultural del Ministerio de Educación, Santiago.

1991. Arte rupestre en la cuenca formativa del río Petorca I. Cerro Tongorito. Actas del XI Congreso Nacional de Arqueología Chilena, pp. 53-6o. Temuco.

Pavlovic, D. y J. Rodríguez, 2005. Nuevas proposiciones sobre el periodo Alfarero Temprano en la cuenca del Choapa.Actas del XVI Congreso Nacional de Arqueología Chilena, pp. 121-130. Tomé.

Pimentel, G., 2006. Evidencias ceremoniales en rutas interregionales prehispánicas que conectaron con San Pedro de Atacama. En Arte americano: Contextos y formas de ver, J. M. Martínez (Ed.), pp. 41-48. Ril Editores, Santiago.

Reichel-Dolmatoff, G., 1985. Aspectos chamanísticos y neurofisiológicos del arte indígena. En Estudios en arte rupestre, C. Aldunate, J. Berenguer y V. Castro (Eds.), pp. 291-307, Museo Chileno de Arte Precolombino, Santiago.

Troncoso, A., 1998. El periodo Intermedio Tardío en la cuenca del río Illapel: Desarrollo y relaciones. Memoria para optar al Título de Arqueólogo. Departamento de Antropología, Universidad de Chile, Santiago.

2003. Proposición de estilos para el arte rupestre del valle de Putaendo, curso superior del río Aconcagua. Chungara 35 (2): 209-231.

Vilches, F., 2006. Arte rupestre y vida cotidiana en Chusmiza, región de Tarapacá. En Arte americano: Contextos y formas de ver, J. M. Martínez (Ed.), pp. 63-68. Ril Editores, Santiago. 